\title{
Determination of left ventricular mass in systemic hypertension: comparison of standard and signal averaged electrocardiography
}

\author{
Dominique Lacroix, Mario Abi Nader, Christine Savoye, Didier Klug, Régis Logier, \\ Salem Kacet, Jean Lekieffre
}

\begin{abstract}
Objective-To investigate the quantitative relationship, if any, between signal averaged electrocardiographic variables and echocardiographically determined left ventricular mass in hypertensive subjects.
\end{abstract}

Design-Cohort analytic prospective study.

Setting-University hospital.

Subjects-50 hypertensive subjects selected consecutively from inpatients. Patients older than 75 years, with underlying cardiac disease, with inconclusive echocardiograms with bundle branch block, or in atrial fibrillation were excluded.

Interventions-Antihypertensive therapy involving 41 patients was continued.

Main outcome measures-Left ventricular mass calculated in accordance with the standards of the Penn convention. Thirteen criteria derived from combinations of signal averaged electrocardiographic X, $\mathbf{Y}$, and $\mathbf{Z}$ Frank orthogonal leads, including voltage criteria, duration, and time-voltage integrals of the QRS complex. Four widely used standard electrocardiographic criteria for detection of left ventricular hypertrophy.

Results-There was no difference in the values for any of the electrocardiographic variables between patients with $(n=29)$ and without left ventricular hypertrophy $(n=21)$. The time-voltage integral of QRS in the horizontal plane was the best signal averaged variable related to left ventricular mass $(r=0.33, P=0.019)$; however, the correlation with Rodstein voltage was stronger $(r=0.46, P=$ 0.0009). A positive correlation was also found between left ventricular indexed mass and Rodstein voltage $(r=0.43, P=$ $0.0019)$. Stepwise regression analysis revealed Rodstein voltage as the only predictor of indexed mass $(P=0.0019)$, and Rodstein voltage $(P=0.0022)$ and body weight $(P=0.011)$ as the only independent correlates of left ventricular mass.

Conclusions-The relation between electrocardiographic variables and left ventricular mass or indexed mass is of limited value; signal averaged orthogonal leads do not improve this assessment compared with standard electrocardiographic leads.
(Br Heart f 1995;74:277-281)

Keywords: left ventricular mass; hypertension standard electrocardiography; signal averaged electrocardiography

Increased left ventricular mass is a powerful predictor of cardiovascular morbidity and mortality in hypertensive patients ${ }^{1}$ and in the general population. ${ }^{2}$ Although standard 12lead electrocardiography remains the most widely used technique for the identification of left ventricular hypertrophy, standard voltage criteria are known to be relatively insensitive at high levels of specificity. Recently, it has been suggested that the use of signal averaged computerised electrocardiography can improve the accuracy for the identification of left ventricular hypertrophy. ${ }^{34}$ However, the quantitative relationship between signal averaged electrocardiographic variables and echocardiographically determined left ventricular mass has not been verified in a prospective fashion in hypertensive subjects. Such was the purpose of this study.

\section{Methods}

$M$ mode and two dimensional echocardiograms, 12-lead electrocardiograms, and signal averaged electrocardiograms were obtained in 50 consecutive hypertensive patients between October 1992 and August 1993. Patients with valvar heart disease, coronary artery disease, cardiomyopathy, or inconclusive echocardiograms were excluded, as were subjects with bundle branch block or who were in atrial fibrillation. Subjects older than 75 years were also excluded. Antihypertensive therapy (41/50 patients treated) was not interrupted at the time of evaluation. Left ventricular mass was calculated in accordance with the strict standards of the Penn convention (Vingmed 750 system with $3.5 \mathrm{MHz}$ transducer, Diasonics Inc). Two dimensional guided $M$ mode measurements were carefully performed by three independent observers; patients in whom the intraobserver variability for left ventricular mass evaluation was $>10 \%$ were excluded. Left ventricular mass (g) was defined as:

$1.04\left[(\mathrm{LVID}+\mathrm{PWT}+\mathrm{VST})^{3}-\mathrm{LVID}^{3}\right]-13.6$

where LVID = end diastolic left ventricular internal dimension, PWT = end diastolic posterior wall thickness, and VST = end diastolic ventricular septal thickness. No patient had 
Table 1 Clinical, morphological and echocardiographic data in men and women with and without left ventricular (LV) hypertrophy. Values are means (SD)

\begin{tabular}{|c|c|c|c|c|c|c|}
\hline & \multicolumn{3}{|l|}{ Men } & \multicolumn{3}{|l|}{ Women } \\
\hline & $L V H$ absent & $L V H$ present & $P$ & LVH absent & $L V H$ present & $P$ \\
\hline 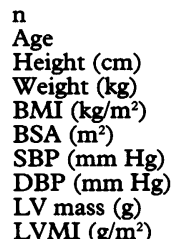 & $\begin{array}{c}13 \\
49 \cdot 2(13 \cdot 8) \\
177(6 \cdot 7) \\
82 \cdot 6(11 \cdot 4) \\
26 \cdot 3(3 \cdot 8) \\
2 \cdot 00(0 \cdot 14) \\
147(9 \cdot 7) \\
91(9 \cdot 5) \\
208(29 \cdot 0) \\
104(12 \cdot 5)\end{array}$ & $\begin{array}{l}12 \\
49 \cdot 1(9 \cdot 4) \\
171(8 \cdot 1) \\
83 \cdot 2(12 \cdot 4) \\
28 \cdot 2(3 \cdot 7) \\
1 \cdot 96(0 \cdot 17) \\
152(22 \cdot 6) \\
96(11 \cdot 9) \\
323(46 \cdot 8) \\
164(25 \cdot 2)\end{array}$ & $\begin{array}{l}\text { NS } \\
\text { NS } \\
\text { NS } \\
\text { NS } \\
\text { NS } \\
\text { NS } \\
\text { NS } \\
0.001 \\
0.001\end{array}$ & $\begin{array}{c}8 \\
43 \cdot 5(15 \cdot 9) \\
161(6 \cdot 8) \\
66 \cdot 1(19 \cdot 3) \\
25 \cdot 4(7 \cdot 4) \\
1.69(0 \cdot 21) \\
146(15 \cdot 1) \\
94 \cdot 6(13 \cdot 4) \\
155(19 \cdot 6) \\
93(12 \cdot 8)\end{array}$ & $\begin{array}{l}17 \\
55 \cdot 9(12 \cdot 2) \\
160(5 \cdot 6) \\
75 \cdot 2(15 \cdot 6) \\
29 \cdot 3(6 \cdot 0) \\
1 \cdot 77(0 \cdot 17) \\
150(29 \cdot 1) \\
92 \cdot 5(20 \cdot 8) \\
273(58 \cdot 9) \\
154(30 \cdot 6)\end{array}$ & $\begin{array}{l}\text { NS } \\
\text { NS } \\
\text { NS } \\
\text { NS } \\
\text { NS } \\
\text { NS } \\
\text { NS } \\
0.001 \\
0.001\end{array}$ \\
\hline
\end{tabular}

BMI, body mass index; BSA, body surface area; DBP and SBP, diastolic and systolic blood pressure under treatment; LVH, left ventricular hypertrophy; LVMI, left ventricular mass indexed to body surface area. bidirectional filter ${ }^{3}$; and QRS duration. Three additional criteria were obtained from the $5 \mathrm{~Hz}$ high pass filtered $\mathrm{Z}$ lead, including the root mean square voltage amplitude, timevoltage integral, and mean voltage amplitude of the QRS complex. ${ }^{3}$ The last variable, recently proposed by Okin et $a l^{4}{ }^{4}$ was the horizontal plane time-voltage integral of the vector magnitude $\left(\mathrm{X}^{2}+\mathrm{Z}^{2}\right)^{\frac{1}{2}}$. For purpose of comparison, four widely used electrocardiographic criteria for the detection of left ventricular hypertrophy were examined. These included the Sokolow-Lyon voltage $\left(S_{1}\right.$ plus $\mathrm{RV}_{5}$ or $\mathrm{RV}_{6}$ ), the Cornell voltage (RaVL plus $\mathrm{SV}_{3}$ ), the sum of $\mathrm{QRS}$ voltage in all 12 leads, and the Rodstein voltage ( $R$ in lead I plus $S$ in lead III).

Means and standard deviations were calcuasymmetrical left ventricular hypertrophy (VST/PWT $<1.5$ in all cases). Left ventricular hypertrophy was considered present if the left ventricular mass indexed to body surface area was $>134 \mathrm{~g} / \mathrm{m}^{2}$ in men and $>110 \mathrm{~g} / \mathrm{m}^{2}$ in women. ${ }^{5}$ According to these criteria, hypertrophy was present in 29 patients (58\%). In 17 of them left ventricular hypertrophy was concentric (2PWT/LVID $>0.45$ ), and it was eccentric in the remaining 12 (2PWT/LVID $<0.45)$. Signal averaged electrocardiograms were recorded at rest in a fasting state from orthogonal bipolar $\mathrm{X}, \mathrm{Y}$ and $\mathrm{Z}$ leads using an Arrhythmia Research Technology 1200EPX high resolution system. After amplification, sampling, and averaging of 150 to 210 cycles (noise level $=0.38 \mu \mathrm{V}$, SD 0.11 ), the data were stored for further processing. Thirteen criteria derived from signal averaged electrocardiography were taken into consideration, nine of which were calculated after combination of the leads into a maximal spatial vector $\left(\mathrm{X}^{2}+\mathrm{Y}^{2}+\mathrm{Z}^{2}\right)^{\frac{1}{2}}$. These criteria were: root mean square voltage amplitude; peak voltage amplitude; time-voltage integral and mean voltage amplitude of the unfiltered QRS complex and of the QRS complex determined at $5 \mathrm{~Hz}$ high pass filtering with a Butterworth lated for the clinical, electrocardiographic, and echocardiographic results. Comparisons of means were made using Student's $t$ test for independent samples. The KolmogorovSmirnov test was used to fit the normal distribution to the echocardiographic variables. The relationship between electrocardiographic criteria and left ventricular mass or indexed mass was determined by correlation analysis. Since regression calculations are based on the assumption that the relationship (if any) between the variables is linear, the assumption of linearity was tested before calculating the correlation coefficients through runs tests. Stepwise regression analysis was used to determine which of the univariate variables were significant independent predictors of left ventricular mass or indexed mass and the strength of these associations.

\section{Results} trophy were different in the two sexes, the means and standard deviations of the clinical, 12-lead and signal averaged electrocardiographic characteristics as well as echocardiographically estimated left ventricular masses
Since the criteria for left ventricular hyper-

Table 2 Electrocardiographic data in men and women with and without left ventricular hypertrophy. Values are means $(S D)$

\begin{tabular}{|c|c|c|c|c|c|c|}
\hline & \multicolumn{3}{|l|}{ Men } & \multicolumn{3}{|l|}{ Women } \\
\hline & $\begin{array}{l}L V M I \\
\left(\mathrm{~g} / \mathrm{m}^{2}\right)\end{array}$ & $\begin{array}{l}L V M I \\
\left(\mathrm{~g} / \mathrm{m}^{2}\right)\end{array}$ & $P$ & $\underset{\left(\mathrm{g} / \mathrm{m}^{2}\right)}{L V M I}<110$ & $\underset{\left(\mathrm{g} / \mathrm{m}^{2}\right)}{L V M I}>110$ & $P$ \\
\hline $\begin{array}{l}\text { Rodstein }(\mathrm{mV}) \\
\text { Cornell }(\mathrm{mV}) \\
2 \mathrm{~V}(\mathrm{mV}) \\
\text { Sokolow (mV) }\end{array}$ & $\begin{array}{l}1.15(0.32) \\
1.58(0.65) \\
1.43(0.44) \\
2.53(1.03)\end{array}$ & $\begin{array}{l}1.38(0.51) \\
1.86(0.54) \\
1.57(0.30) \\
2.62(0.84)\end{array}$ & $\begin{array}{l}\text { NS } \\
\text { NS } \\
\text { NS } \\
\text { NS }\end{array}$ & $\begin{array}{l}1.19(0.33) \\
1.31(0.31) \\
1.33(0.48) \\
2.37(1.16)\end{array}$ & $\begin{array}{l}1.57(0.78) \\
1.79(0.82) \\
1.39(0.48) \\
2.27(0.86)\end{array}$ & $\begin{array}{l}\text { NS } \\
\text { NS } \\
\text { NS } \\
\text { NS }\end{array}$ \\
\hline $\begin{array}{l}\text { QRS duration (ms) } \\
0-250 \mathrm{~Hz} \text { PVA (mV) } \\
0-250 \mathrm{~Hz} \text { RMSA (mV) } \\
0-250 \mathrm{~Hz} \text { TVI }(\mu \mathrm{V} . \mathrm{s}) \\
0-250 \mathrm{~Hz} \text { MVA (mV) } \\
5-250 \mathrm{~Hz} \text { PVA (mV) } \\
5-250 \mathrm{~Hz} \text { RMSA }(\mathrm{mV}) \\
5-250 \mathrm{~Hz} \text { TVI }(\mu \mathrm{V} . \mathrm{s}) \\
5-250 \mathrm{~Hz} \text { MVA (mV) } \\
5-250 \mathrm{~Hz} \mathrm{RMSA}_{\mathrm{z}}(\mathrm{mV}) \\
5-250 \mathrm{~Hz} \mathrm{TVI}_{\mathrm{z}}(\mu \mathrm{V} . \mathrm{s}) \\
5-250 \mathrm{~Hz} \mathrm{MVA}_{\mathrm{z}}(\mathrm{mV}) \\
0-250 \mathrm{~Hz} \mathrm{TVI}_{\mathrm{HP}}(\mu \mathrm{V} . \mathrm{s})\end{array}$ & $\begin{array}{c}104(8.6) \\
2.87(1.12) \\
1.27(0.51) \\
88.8(33.5) \\
0.85(0.33) \\
1.59(0.54) \\
0.66(0.21) \\
44.5(12.7) \\
0.43(0 \cdot 12) \\
0.43(0.19) \\
28.7(12.5) \\
0.28(0 \cdot 12) \\
73.2(29.0)\end{array}$ & $\begin{array}{c}99(1 \cdot 7) \\
2.87(0.88) \\
1.34(0.34) \\
92 \cdot 2(21 \cdot 2) \\
0.92(0 \cdot 19) \\
1.67(0.50) \\
0.72(0.22) \\
45 \cdot 5(10 \cdot 2) \\
0.45(0 \cdot 10) \\
0.40(0 \cdot 22) \\
24.4(13.8) \\
0.24(0.13) \\
76.8(21.4)\end{array}$ & $\begin{array}{l}\text { NS } \\
\text { NS } \\
\text { NS } \\
\text { NS } \\
\text { NS } \\
\text { NS } \\
\text { NS } \\
\text { NS } \\
\text { NS } \\
\text { NS } \\
\text { NS } \\
\text { NS } \\
\text { NS }\end{array}$ & $\begin{array}{c}92(6 \cdot 1) \\
2.85(1.48) \\
1.24(0.59) \\
73.6(33.8) \\
0.79(0.32) \\
1.59(0.78) \\
0.72(0.36) \\
40.7(18.9) \\
0.44(0.18) \\
0.43(0.25) \\
23.7(11.9) \\
0.25(0.16) \\
61.0(22.5)\end{array}$ & $\begin{array}{c}97(8.8) \\
2.39(0.92) \\
1.14(0.49) \\
77.6(31.5) \\
0.79(0.30) \\
1.27(0.38) \\
0.57(0.19) \\
37.9(13.2) \\
0.39(0.13) \\
0.34(0.16) \\
22.1(11 \cdot 7) \\
0.25(0.11) \\
68.6(28.6)\end{array}$ & $\begin{array}{l}\text { NS } \\
\text { NS } \\
\text { NS } \\
\text { NS } \\
\text { NS } \\
\text { NS } \\
\text { NS } \\
\text { NS } \\
\text { NS } \\
\text { NS } \\
\text { NS } \\
\text { NS } \\
\text { NS }\end{array}$ \\
\hline
\end{tabular}

LVMI, left ventricular mass indexed to body surface area; MVA, mean voltage amplitude of the maximal spatial vector; MVA $_{z}$ mean voltage amplitude on $Z$ lead; PVA, peak voltage amplitude of the maximal spatial vector; RMSA, root mean square voltage amplitude of the maximal spatial vector; $\mathrm{RMSA}_{\mathrm{z}}$, root mean square voltage amplitude on Z lead; TVI, time-voltage integral of the maximal spatial vector; $\mathrm{TVI}_{\mathrm{HP}}$, time-voltage integral in the horizontal plane; $\mathrm{TVI}_{\mathrm{Z}}$, time-voltage integral on $\mathrm{Z}$ lead; $2 \mathrm{~V}$, sum of $Q R S$ voltage in all 12 leads. 
were listed separately in men and women in tables 1 and 2. The distributions of left ventricular masses and indexed masses are shown in fig 1 ; neither cumulative distribution function differed significantly from normal distributions. The means of signal averaged and standard electrocardiographic variables were not significantly different among men and

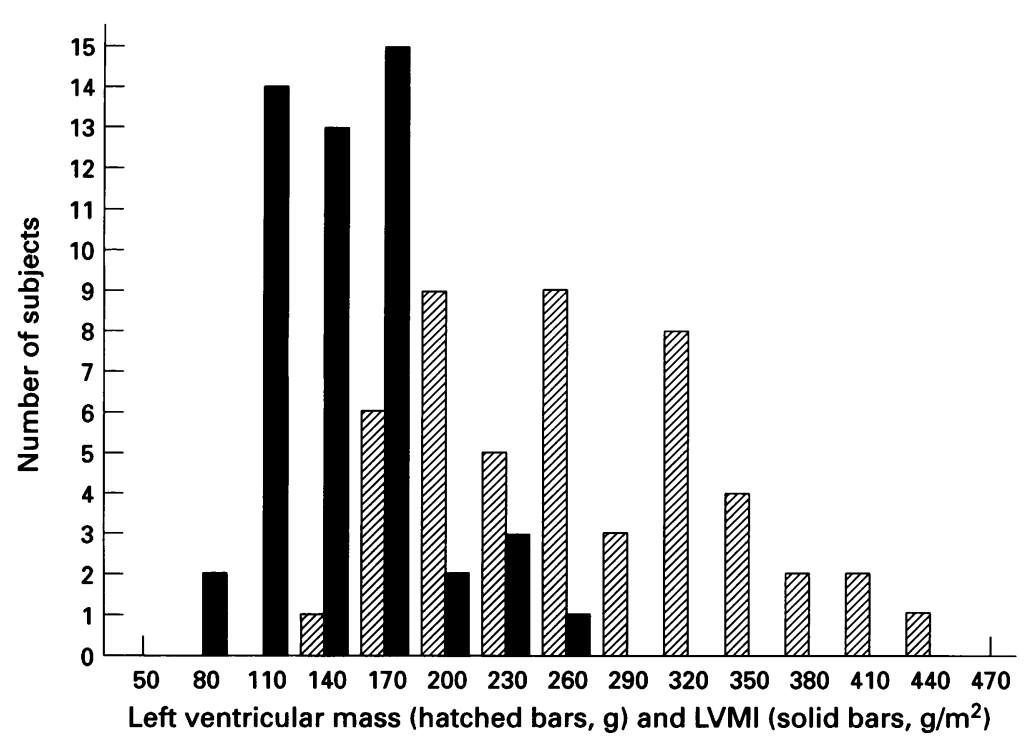

Figure 1 Left ventricular mass and indexed mass in the population studied.
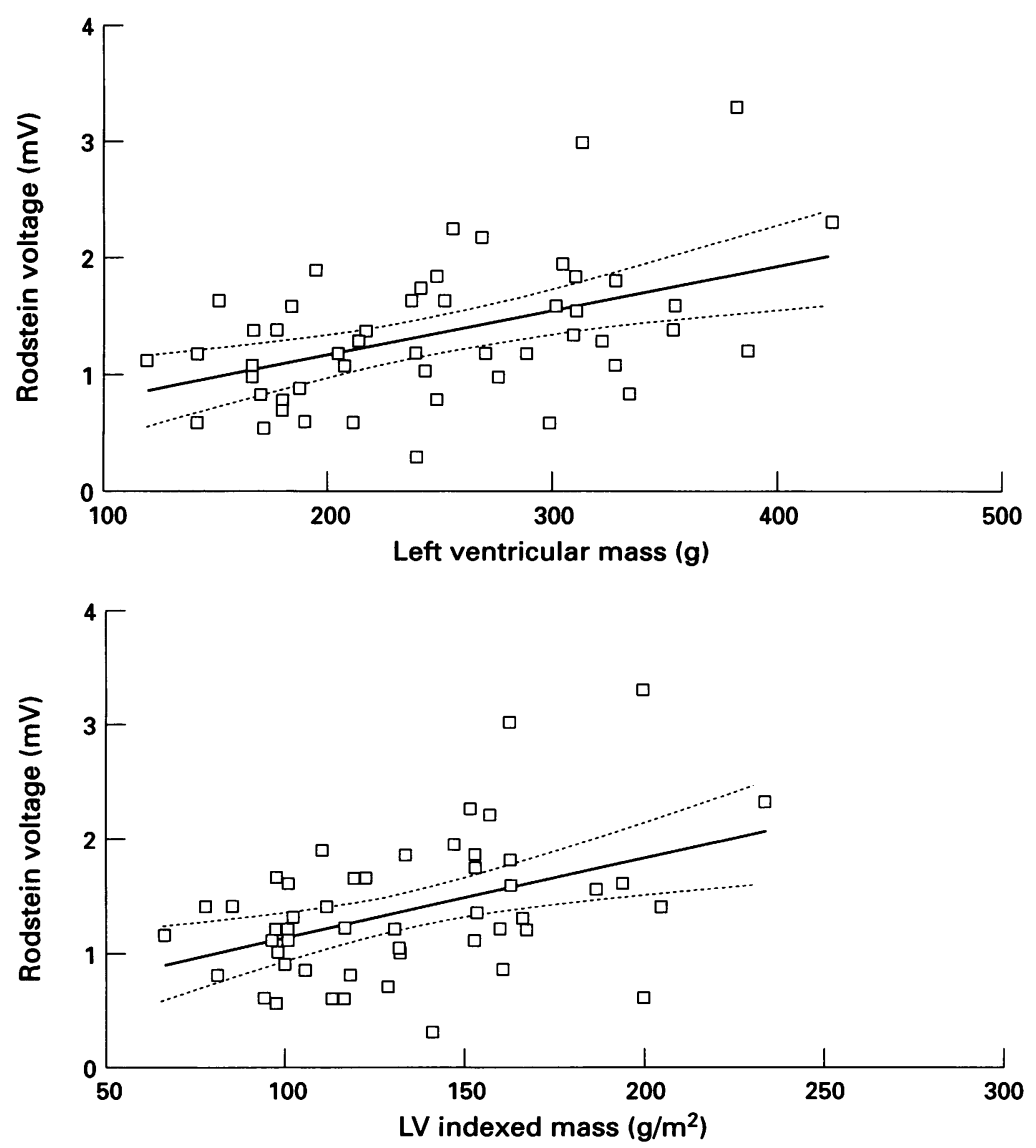

Figure 2 Upper panel: relation between left ventricular mass and Rodstein voltage $(r=0.46, P=0.0009)$. Lower panel: relation between left ventricular indexed mass and Rodstein voltage $(r=0.43, P=0.0019)$. Solid line: linear regression line, dotted lines: $95 \%$ confidence interval. women between patients with and without hypertrophy.

Left ventricular mass being a continuous variable, the clustering of the values near the hypertrophy cutpoints suggested that a correlation analysis between electrocardiographic variables and left ventricular mass or indexed mass would be of interest. These results are summarised in table 3 . Left ventricular mass was found to correlate positively and linearly with the time-voltage integral of the maximal spatial vector complex, the horizontal plane time-voltage integral, and the Cornell and Rodstein voltages (fig 2). Positive linear correlations were also found between left ventricular indexed mass and Rodstein voltage (fig 2) or Cornell voltage. The linearity of these relations was always confirmed and discouraged the use of non-linear or polynomial equations. The strongest association was characterised by the following linear regression equation: left ventricular mass $(\mathrm{g})=(56.3 \times$ Rodstein voltage $)$ +173 , with standard error $(\mathrm{SE})=66.3 \mathrm{~g}$.

Correlations were also observed between left ventricular mass and body weight $(r=$ $0.39, \mathrm{P}=0.0046)$, body surface area $(r=$ $0.32, \mathrm{P}=0.023)$, or body mass index $(r=$ $0.41, P=0.0033$ ).

Stepwise regression analysis including age and morphological and electrocardiographic variables identified only two significant independent predictors of left ventricular mass: Rodstein voltage $(P=0.0022)$ and body weight ( $P=0.011)$ (in that order). The linear equation was: left ventricular mass $(\mathrm{g})=(1.5$ $\times$ body weight $)+(49 \times$ Rodstein voltage $)$ +66 . This final regression model was characterised by an adjusted correlation coefficient $r=0.53$, with residual $\mathrm{SE}=62.5 \mathrm{~g}$ (fig 3). When compared to the simple regression equation obtained with ventricular mass and Rodstein voltage, adding body weight to the

Table 3 Correlation analysis between electrocardiographic variables and left ventricular mass and indexed mass

\begin{tabular}{|c|c|c|c|c|}
\hline & \multicolumn{2}{|c|}{$L V$ mass } & \multicolumn{2}{|c|}{$L V$ indexed mass } \\
\hline & $r$ & $P$ & $r$ & $P$ \\
\hline $\begin{array}{l}\text { Rodstein (mV) } \\
\text { Cornell (mV) } \\
\Sigma \mathrm{V}(\mathrm{mV}) \\
\text { Sokolow (mV) }\end{array}$ & $\begin{array}{c}0.46 \\
0 \cdot 36 \\
0 \cdot 25 \\
0 \cdot 15\end{array}$ & $\begin{array}{l}0.0009 \\
0.012 \\
\text { NS } \\
\text { NS }\end{array}$ & $\begin{array}{l}0 \cdot 43 \\
0 \cdot 34 \\
0 \cdot 21 \\
0 \cdot 12\end{array}$ & $\begin{array}{l}0.0019 \\
0.016 \\
\text { NS } \\
\text { NS }\end{array}$ \\
\hline $\begin{array}{l}\text { QRS duration (ms) } \\
0-250 \mathrm{~Hz} \text { PVA }(\mathrm{mV}) \\
0-250 \mathrm{~Hz} \text { RMS }(\mathrm{mV}) \\
0-250 \mathrm{~Hz} \text { TVI }(\mu \mathrm{V} . \mathrm{s}) \\
0-250 \mathrm{~Hz} \text { MVA }(\mathrm{mV}) \\
5-250 \mathrm{~Hz} \text { PVA (mV) } \\
5-250 \mathrm{~Hz} \text { RMSA (mV) } \\
5-250 \mathrm{~Hz} \text { TVI }(\mu \mathrm{V} . \mathrm{s}) \\
5-250 \mathrm{~Hz} \text { MVA }(\mathrm{mV}) \\
5-250 \mathrm{~Hz} \text { RMSA }(\mathrm{mV}) \\
5-250 \mathrm{~Hz} \text { TVI }(\mu \mathrm{V} . \mathrm{s}) \\
5-250 \mathrm{~Hz} \mathrm{MVA}_{\mathrm{z}}(\mathrm{mV}) \\
0-250 \mathrm{~Hz} \mathrm{TVI}_{\mathrm{HP}}(\mu \mathrm{V} . \mathrm{s})\end{array}$ & $\begin{array}{l}0 \cdot 21 \\
0 \cdot 04 \\
0 \cdot 17 \\
0 \cdot 31 \\
0 \cdot 24 \\
0 \cdot 05 \\
0 \cdot 11 \\
0 \cdot 21 \\
0 \cdot 17 \\
0 \cdot 10 \\
0 \cdot 14 \\
0 \cdot 10 \\
0 \cdot 33\end{array}$ & $\begin{array}{l}\text { NS } \\
\text { NS } \\
\text { NS } \\
0 \cdot 027 \\
\text { NS } \\
\text { NS } \\
\text { NS } \\
\text { NS } \\
\text { NS } \\
\text { NS } \\
\text { NS } \\
\text { NS } \\
0.019\end{array}$ & $\begin{array}{l}0.06 \\
0.02 \\
0 \cdot 13 \\
0 \cdot 18 \\
0 \cdot 17 \\
0.007 \\
0 \cdot 12 \\
0 \cdot 14 \\
0 \cdot 13 \\
-0.002 \\
0.02 \\
0 \cdot 01 \\
0 \cdot 24\end{array}$ & $\begin{array}{l}\text { NS } \\
\text { NS } \\
\text { NS } \\
\text { NS } \\
\text { NS } \\
\text { NS } \\
\text { NS } \\
\text { NS } \\
\text { NS } \\
\text { NS } \\
\text { NS } \\
\text { NS } \\
\text { NS }\end{array}$ \\
\hline
\end{tabular}

LV, left ventricular; MVA, mean voltage amplitude of the maximal spatial vector; $M V A_{z}$, mean voltage amplitude on $Z$ lead; PVA, peak voltage amplitude of the maximal spatial vector; $l$, linear correlation coefficient; RMSA, root mean square voltage amplitude of the maximal spatial vector; time-voltage inean square voltage amplitude on $Z$ lead; $T V$ time-voltage integral of the maximal spatial vector; $\mathrm{TVI}_{\mathrm{HP}}$, age integral on $\mathrm{Z}$ lead; $\Sigma \mathrm{V}$, sum of $\mathrm{QRS}$ voltage in all 12 leads. 


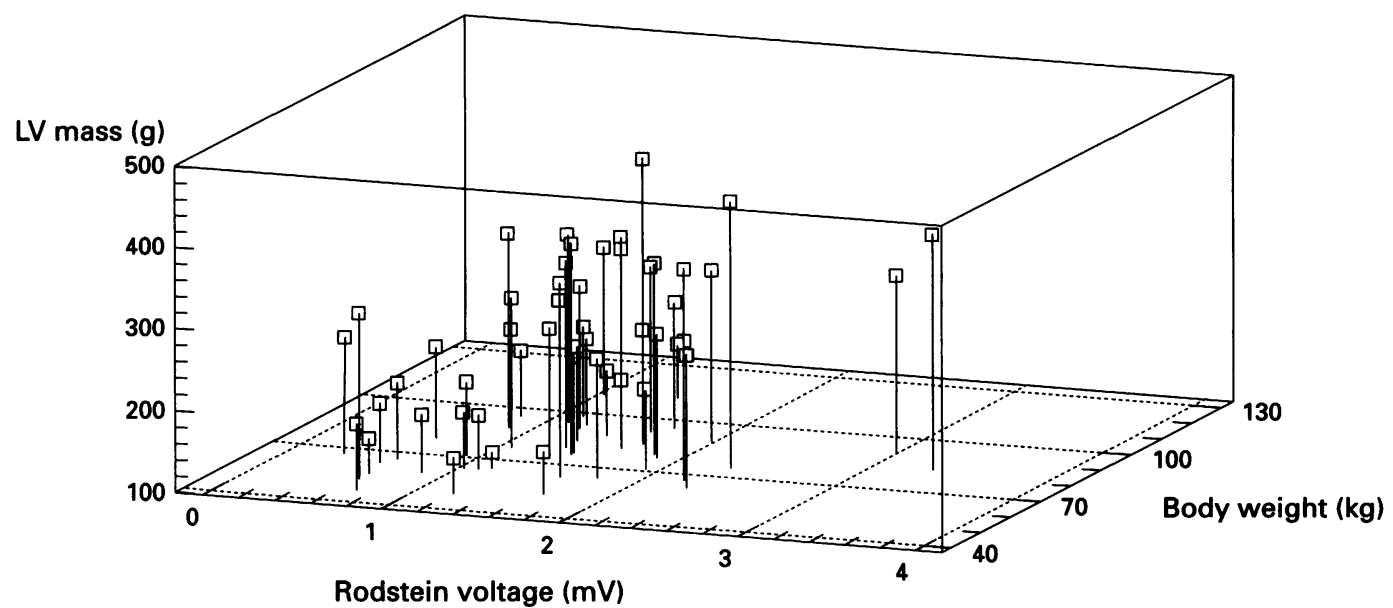

Figure 3 Multiple regression between left ventricular mass, Rodstein voltage, and body weight. The final regression model is: left ventricular mass $=(1.5$ body weight $)+(49$ Rodstein voltage $)+66$. Adjusted correlation coefficient is $r=0.53$ with $S E=62.5 \mathrm{~g}$.

model slightly improved this standard error from 66.3 to $62.5 \mathrm{~g}$. Similarly, Rodstein voltage was found to be the only independent predictor of left ventricular indexed mass (adjusted $r=0.41, \mathrm{P}=0.0019$, and $\mathrm{SE}=$ $\left.34.4 \mathrm{~g} / \mathrm{m}^{2}\right)$. The linear regression equation was: indexed mass $\left(\mathrm{g} / \mathrm{m}^{2}\right)=(27 \times$ Rodstein voltage) +97 .

\section{Discussion}

The diagnosis of left ventricular hypertrophy is a simplified concept, implying the existence of a clearcut demarcation between normality and abnormality. Actually, left ventricular mass covers a continuous spectrum ranging from subnormal at one end to severely hypertrophied at the other. Thus quantitation is a more general aspect of the task of evaluating the left ventricular condition. The results of this study underscore the weakness of electrocardiographic voltage criteria in quantifying left ventricular hypertrophy; our conclusions, however, do not rule out the possible clinical value of these criteria in detecting hypertrophic states. Despite a wide range of left ventricular mass in our population, the relative proportion of patients with borderline echocardiographic hypertrophy was high. This explanation may account for the absence of significant differences in the values of voltage criteria when patients were separated according to the absence or presence of hypertrophy.

The results of our study concerning the usefulness of signal averaged electrocardiographic criteria to assess left ventricular mass conflict with those of Vacek et al. ${ }^{3}$ The criteria advocated by Vacek were the time-voltage integral of the $5-250 \mathrm{~Hz}$ high pass filtered QRS complex, computed either from the vector sum or from the $\mathrm{Z}$ lead alone. We found that these variables did not correlate with left ventricular mass and their mean values did not differ significantly between patients with and without hypertrophy. This disagreement led us to examine whether our population had been chosen appropriately. The first observation was that only unselected and hypertensive subjects had been consecutively recruited in order to test our hypothesis in a clinical and realistic condition. The span of left ventricular masses in our population was also compared with other studies ${ }^{34}$ and did not differ significantly, as evidenced by variance comparison tests ( $F$ tests). In addition, severe left ventricular hypertrophy (indexed mass $>208 \mathrm{~g} / \mathrm{m}^{2}$ in men or $162 \mathrm{~g} / \mathrm{m}^{2}$ in women $)^{6}$ was identified in seven of our patients $(14 \%)$.

The explanation for the discrepancy with Vacek's results could lie in the fact that the cohort prospectively studied by this author was restricted to 20 patients, 14 of whom had normal hearts. An alternative explanation could be related to identical blood pressure levels in our patients with and without hypertrophy (due to the continuation of antihypertensive treatment), whereas neither blood pressure levels nor haemodynamic data were mentioned by Vacek et al. Intraventricular and transmural pressures are in fact thought to participate in the mechanism of voltage increase during left ventricular hypertrophy. ${ }^{?}$

On the other hand, our results are in agreement with those of Okin et $a l,{ }^{4}$ obtained in men presenting with left ventricular hypertrophy and regurgitant valvar heart disease. These investigators reported that the horizontal plane time-voltage integral of the unfiltered QRS complex was a promising index for detecting left ventricular hypertrophy, but unfortunately no correlation was attempted between the values obtained and left ventricular mass. In our study conducted in hypertensive subjects, this variable was the best signal averaged electrocardiographic correlate of left ventricular mass; however, the correlation between left ventricular mass and Rodstein voltage was stronger, as revealed by multivariate analysis. 
The superiority of 12-lead electrocardiograms over computerised high resolution signal averaged electrocardiograms strongly suggests that othogonal $\mathrm{X}, \mathrm{Y}$, and $\mathrm{Z}$ leads (separate or combined) are inadequate to assess left ventricular mass in treated hypertensive subjects. This hypothesis is supported by previous studies examining the heart as a multiple dipole electrical source which have shown an improvement in left ventricular mass quantitation over conventional electrocardiographic or vectocardiographic techniques. In the series of 72 patients studied by Holt et $a l^{8}$ the standard vectocardiographic time-voltage integral was correlated with the angiographically determined left ventricular mass $(r=0 \cdot 77, \mathrm{SE}=80 \mathrm{~g})$ but the use of a realistic model with 12 dipoles dramatically increased the strength of the correlation $(r=$ $0.93, \mathrm{SE}=49 \mathrm{~g}) .^{6}$

In conclusion, the relation between electrocardiographic variables and left ventricular mass is of limited value for the purpose of quantitation. Signal averaged electrocardiography obtained from three orthogonal leads does not improve this assessment compared to standard electrocardiography.
This work was supported by grants from the Fédération Française de Cardiologie and the Société Francaise de Cardiologie, Paris, France. We are grateful to François Tricot MD, Hugo Reyford MD, and Luc Goullard MD for invaluable technical help. We thank Véronique Leleu and Emmanuelle Lamerant for secretarial assistance.

1 Koren MJ, Devereux RB, Casale PN, Savage DD, Laragh $\mathrm{JH}$. Relation of left ventricular mass and geometry to morbidity and mortality in men and women with uncomplicated essential hypertension. Ann Intern Med 1991;114:345-52.

2 Levy D, Garrison RJ, Savage DD, Kannel WB, Castelli WP. Prognosis implications of echocardiographically determined left ventricular mass in the Framingham Heart Study. N Engl ₹ Med 1990;322:1561-6.

3 Vacek $J$, Wilson DB, Botteron GW, Dobbins J. Techniques for the determination of left ventricular mass by signal-averaged electrocardiography. Am Heart f 1990;120:958-63.

4 Okin PM, Roman MJ, Devereux RB, Borer JS, Kligfield P. Electrocardiographic diagnosis of left ventricular hyperElectrocardiographic diagnosis of left ventricular hyper-
trophy by the time-voltage integral of the QRS complex. trophy by the time-voltage integral

5 Devereux RB, Lutas EM, Casale PN, Kligfield P, Eisenberg RR, Hammond IW, et al. Standardization of $M$-mode echocardiographic left ventricular anatomic measurements. $f$ Am Coll Cardiol 1984;4:1653-9.

6 Savage DD, Garrison RJ, Kannel WB, Levy D, Anderson SJ, Sokes J, et al. The spectrum of left ventricular hypertrophy in a general population sample: the Framingham Study. Circulation 1987;75(suppl I):I-26-33.

7 Fisch C. Electrocardiography and vectorcardiography. In: Braunwald E, ed. Heart disease. Philadelphia: WB Saunders, 1984: 195-258.

8 Holt JH, Barnard ACL, Lynn S. A study of the human heart as a multiple dipole electrical source. II. Diagnosis and quantitation of left ventricular hypertrophy. Circulation 1969;40:697-710. 